\title{
Distinción, descanso y confort: los grandes hoteles como avanzada de la Argentina turística (1886-1914)
}

\author{
Distinction, rest and comfort: Grand Hotels as an outpost of \\ tourism in Argentina (1878-1914) \\ Mercedes González Bracco \\ Universidad de Buenos Aires \\ Santiago Pérez Leloutre \\ Universidad de Buenos Aires/Universidad Torcuato Di Tella
}

\section{DOI: https://doi.org/10.250.32/crh.v6i10.2}

Recibido: 29/03/2020

Aprobado: 06/05/2020

Resumen. Hacia fines del siglo xIX, empresarios pioneros dieron nombre y forma a nuevos espacios y territorios a partir de la instalación de grandes hoteles, edificios significativos no solo por su dimensión sino también por su voluntad de generar un nuevo tipo de sociabilidad vinculada al descanso terapéutico y al ocio mundano en territorios «vacíos». Con la hipótesis de que este proceso contribuyó al conocimiento y domesticación de áreas del país hasta entonces poco exploradas, este trabajo propone estudiar los grandes hoteles construidos en el territorio argentino entre fines del siglo XIX hasta fines de la Primera Guerra Mundial profundizando tanto en las redes de relaciones que facilitaron dichos emprendimientos como en las lógicas de composición de los complejos edilicios, espacios y servicios necesarios para su funcionamiento autónomo.

Palabras claves: grandes hoteles - historia del turismo - infraestructura turística

\footnotetext{
Abstract: Towards the end of the 19th Century, pioneering businessmen gave name and form to new spaces and territories from the installation of "grand hotels", significant buildings not only for their size but also for their willingness to generate a new type of sociability linked to therapeutic rest and worldly leisure in "empty"
} 
territories. Given the hypothesis that this process contributed to the knowledge and domestication of areas of the country until then little explored, this paper aims to study the grand hotels built in the Argentinian territory between the end of the 19th century until the end of the First World War, deepening both the networks of relationships that facilitated these ventures and the logic of composition of the building complexes, spaces and necessary services for autonomous operation.

Keywords: grand hotels - tourism history - touristic infrastructure

\section{Introducción: el turismo como forma de conquista del territorio}

Si bien el desarrollo del turismo como política de Estado se inicia a partir de la década del veinte, es posible rastrear las primeras infraestructuras ligadas a esta práctica desde fines del siglo XIX. El desarrollo del ferrocarril junto a la visión de empresarios pioneros como Pedro Luro, Patricio Peralta Ramos y Ernesto Tornquist, entre otros, dieron nombre y forma a nuevos espacios y territorios a partir de la instalación de grandes hoteles (en adelante, GH). Estos edificios resultan significativos no solo por su dimensión sino también por su voluntad de generar un nuevo tipo de sociabilidad vinculada al descanso terapéutico y al ocio mundano, en territorios muchas veces inhóspitos y sin urbanizar, por lo que las estrategias para su autosustentación eran vitales para su éxito.

La bibliografía que aborda los inicios del turismo en la Argentina menciona algunos elementos que permiten dimensionar la magnitud de este proceso, destacando que se trata del período de esplendor de la hotelería de lujo. ${ }^{1}$ En este sentido, las primeras instalaciones turísticas estuvieron destinadas a las clases altas, que ya contaban con experiencias similares en Europa, donde el desarrollo del Grand Tour había propiciado una nueva forma de entender los viajes. ${ }^{2}$ De este modo, la idea del reposo saludable, que durante el siglo XIX había dado inicio a los complejos termales

\footnotetext{
${ }^{1}$ Elisa Pastoriza, La conquista de las vacaciones. Breve historia del turismo en la Argentina, Buenos Aires, Edhasa, 2011; Bruno, Perla, «Los hoteles de turismo (1930-1955): piezas claves del territorio turístico de la Argentina», Registros, Año 8, N. ${ }^{\circ}$ 9, 2012, pp. 54-80.

${ }^{2}$ Lynne, Withey, Grand tours and Cook's tours: a history of leisure travel, 1750 to 1915, Nueva York, William Morrow and Company, 1997; Hanley, Keith y Walton, John, Constructing Cultural Tourism: John Ruskin and the Tourist Gaze, Bristol, Buffalo y Toronto, Channel View Publications, 2010.
} 
junto a los baños de mar y de sol, comenzó a solaparse con nuevas formas de distinción que implicaban la participación en reuniones y diversiones que se trasladaban a otras geografías para aprovechar las bellezas naturales durante la temporada estival o invernal.

No obstante, la intención de desarrollar estas construcciones suntuarias se vio matizada por el acceso efectivo a dichas instalaciones. Por ejemplo, para mediados del siglo XIX un viaje a las quintas veraniegas del norte de la ciudad de Buenos Aires implicaba un tortuoso trayecto en carreta de una jornada. Recién en 1865 la llegada del ferrocarril permitió llegar a las zonas de recreos en el Tigre en algo más de una hora (Losada 2008). El rápido desarrollo de este medio de transporte transformó la manera de concebir el territorio nacional, y el turismo fue una de las formas en que se domesticó el espacio hasta entonces considerado «salvaje», «peligroso» o simplemente «vacío» (Corbin 1993).

A partir de estas coordenadas, este trabajo se propone estudiar a los «grandes hoteles» construidos en el territorio nacional entre fines del siglo XIX hasta la primera guerra mundial, como infraestructuras de avanzada que contribuyeron a fomentar un cambio de mirada y de usos sobre nuevos territorios. Para ello, profundizaremos tanto en sus aspectos materiales, como en los sentidos sociales y culturales adscritos quiénes los idearon, quiénes fueron los usuarios, qué ocurría en estos espacios-.

Respecto a los estudios previos, hemos observado que existe una gran disparidad en la cantidad y profundidad de trabajos que abordan los diversos hoteles que aquí se mencionan. Asimismo, aquellos trabajos abocados específicamente a los GH del período se han desarrollado de forma atomizada. ${ }^{3}$ Sin embargo, la información disponible permite dar forma a la hipótesis que nos lleva a pensarlos como un conjunto, en tanto novedosas formas de instauración de lo metropolitano en un territorio considerado virgen.4 Con esta idea se indagarán los discursos, relatos,

\footnotetext{
3 Entre ellos, Juan Pablo de Toni, Eden Hotel. El nacimiento de un pueblo, Córdoba, Editorial EH, 2007; Alberto Domínguez, La ciudad de invierno. Un símbolo de la belle époque, Corrientes, Moglia Ediciones, 2007; Stella Maris Rodríguez y Sergio Rodríguez, Club Hotel de la Ventana. La historia de un gigante, Buenos Aires, Ediciones Pensamiento, 2001; Jorge Alberto Jordi y Lisandro Fausto Victoria, Nacimiento y muerte de la maravilla del siglo XX. Club Hotel de la Ventana, Buenos Aires, Dunken, 2009; Lilia Zenequelli, El Tigre Hotel y el Tigre Club, Buenos Aires, Dunken, 2005.

4 Si bien el desarrollo local de los GH se espeja en programas arquitectónicos ensayados en las grandes capitales europeas y centros termales, la vocación de conquista del territorio nos lleva a ligarlos con aquellos desarrollos llevados a cabo por las potencias coloniales en sus dominios. Al respecto puede
} 
imágenes e imaginarios que operaron en cada caso, observando las estrategias desarrolladas para proyectos emplazados en lugares más o menos suburbanos pero ya consolidados (como el Hotel Plaza en Buenos Aires o el Tigre Hotel) en contraposición a aquellas necesarias para instalar un destino o un concepto (Hotel Bristol en Mar del Plata, Hotel Edén en La Falda, Club Hotel de la Ventana en Sierra de la Ventana). Aquí la pregunta abarca tanto las redes de contactos entre empresarios y arquitectos como los diversos sentidos que comienzan a desarrollarse en torno a estos espacios: convalecencia, recuperación, aventura, reunión, diversión, confort, lujo.

Por otro lado se entrelazarán las improntas antedichas con sus características espaciales y estéticas como formas de expresar un programa que, cuando no se implantaba en las ciudades sino en territorios considerados vírgenes, buscaba expresar la síntesis de ambas. Ya que tales complejos funcionaban como representaciones de la cultura metropolitana en lugares recónditos del país, pero al mismo tiempo se buscaba construir ámbitos de ocio alejados de las grandes urbes, inspirados en las condiciones naturales donde se implantaban.

\section{La Argentina turística en el cambio de siglo: imágenes y miradas en construcción}

Para comprender cómo era percibido el territorio en el período estudiado, tomamos como punto de partida la palabra de Jules Huret, viajero francés que recorrió el país entre 1909 y 1910, y que indicaba la pobre promoción que le ofrecían del interior del país: «Los nombres de las ciudades lejanas de Tucumán, Salta y Jujuy resuenan en mis oídos con un ruido de silbido de locomotora. Quiero verlo todo, pero alguien me dice: -Esas provincias pobres, todavía sin explotar, no encontrará usted nada digno de curiosidad. Perderá usted el tiempo ».5 Estas palabras son constatadas por este autor al llegar a destino: «Henos pues, en Tucumán [...] iAh! Para ser sinceros debemos decir que en cuanto se deja Buenos Aires hay que despedirse de la vida confortable y de Europa». 6 Como bien observa el autor, el territorio que se abre con mayor

consultarse Brian McLaren, «De Trípoli a Gadames: arquitectura y la experiencia turística de la cultura local en la Libia colonial italiana», en: Medina Lasansky, D. y McLaren, B. (eds.), Arquitectura y turismo. Percepción, representación y lugar, Barcelona, Gustavo Gili, 2006.

5 Huret, Jules, De Buenos Aires al Gran Chaco, Buenos Aires, Hyspamérica, 1986 [1911], p. 179.

${ }^{6}$ Ibídem, p. 187. 
disponibilidad gracias a la llegada del ferrocarril se encuentra sin embargo aún poco domesticado.

No obstante, cabe aclarar que la Buenos Aires descrita por Huret distaba de ser una metrópolis acabada. Se trataba más bien de una ciudad moderna, sí, pero en plena ebullición edilicia, en la que persistían muchos contrastes. Él se alojó en el Plaza Hotel, de reciente construcción, que claramente se distinguía en un escenario donde primaba el desbalance:

Desde el muelle, una sola construcción hace dirigir la vista hacia la ciudad. Es el último hotel edificado, el Plaza Hotel, edificio de siete pisos que destaca su blancura en el azul del cielo [...] En la avenida Alvear hermosas casas particulares tienen por vis a vis, y como vecinas, viejos tenduchos bajos [...] Al lado de hermosas villas que son verdaderos castillos, se ven terrenos sin urbanizar donde pacen caballos... ${ }^{7}$

El viajero francés resaltaba además la falta de detalles pintorescos (la ciudad no cuenta con colinas, accidentes geográficos, conexión con el río) y la ausencia de exotismo (la gente habla francés, su modo de vestir y las formas de relacionarse se parecen mucho a la de ciudades europeas). En este sentido, Buenos Aires no resultaba atractiva a sus ojos, algo que subsanó con la llegada a las provincias del norte, donde sí encontró el paisaje y los personajes exóticos que había imaginado al partir de su tierra natal. Su mirada era ya una mirada turística que buscaba experimentar lo ajeno pero con ciertos estándares de comodidad ¿Cómo armonizar entonces la búsqueda de lo pintoresco y la necesidad del confort?

En 1913 Caras y Caretas publicó fragmentos de su segundo volumen de viajes, mostrando sus impresiones sobre algunos lugares de veraneo. El contacto con la naturaleza se hacía necesario debido al «calor sofocante, los vapores que suben del caldeado río y ponen pesada la atmósfera, la especie de sopor que se apodera de los más resistentes, (que) obligan á todos los que pueden hacerlo a huir de la ciudad» 8 (65). Los sauces del Tigre, las sierras de Córdoba y las frescas brisas del océano de Mar del Plata resultaban así un reposo del calor urbano. Sin embargo, de Mar del Plata rescató «sus suntuosas villas, su único y vasto hotel-casino, en que se reúnen, durante algunas semanas todas las fortunas, todas las elegancias, todos los joyeles de la

8 "La sociedad argentina", Caras y Caretas [Buenos Aires] N. ${ }^{\circ} 750$, febrero 15, 1913, p. 65. 
Argentina». $9 \mathrm{El}$ viajero enfatizó la centralidad del hotel-casino como espacio de ocio y negocios, de sociabilidad, de mezcla de provincianos y capitalinos, mostrando el veraneo en la ciudad como la traslación de las mismas costumbres porteñas al mar. Por el contrario, el Tigre brindaba un tipo de ocio «sencillo», donde los deportes, los árboles y los canales se entremezclaban con construcciones aisladas, tipo cottages: «Se olvida Buenos Aires, Mar del Plata, el Colón, los clubs, para ceder al encanto de esa naturaleza casi virgen, de magnífica exuberancia ${ }^{10}$ a solo media hora de distancia de la capital.

Las impresiones de Huret sirven para poner en escena las particularidades y los contrastes de un momento lleno de avances arrolladores y precariedades persistentes que, de manera dispar, pueden observarse a lo largo del territorio nacional. La vocación de modernizar el país también forma parte de la necesidad de, parafraseando a Marta Penhos, ver, conocer y dominar los territorios ya anexados pero aun considerados vacíos o vírgenes. ${ }^{11}$ La novedad del período está dada por un cambio de mirada sobre estos. Si desde mediados del siglo XIX los avances tecnológicos estaban puestos exclusivamente en favor del desarrollo productivo de la tierra - lo que se manifiesta en el trazado del ferrocarril-, poco a poco la reconversión del paisaje natural en recurso económico abre las puertas a otro tipo de empresas: comienza entonces el negocio del ocio.

\section{3. «Un ferrocarril y un hotel»: redes y herramientas para la creación de un lugar imaginado}

El arco de GH que aquí se analizan se abre con la construcción del Hotel Casino Termas Rosario de la Frontera (1886-1896) en la localidad homónima, y contiene al Bristol Hotel (Mar del Plata, 1886-1888), Boulevard Atlántico (Mar del Sud, 18891891), Tigre Hotel (Tigre, circa 1890), Hotel Edén (La Falda, 1897-1898), Hotel Puente del Inca (1903), Club Hotel de la Ventana (Sierra de la Ventana, 1904-1911), Plaza Hotel

\footnotetext{
9 Idem.

${ }^{10}$ Idem.

${ }^{11} \mathrm{El}$ desarrollo de parques nacionales fue otra de las estrategias llevadas adelante con este fin (Eugenia Scarzanella, «Las bellezas naturales y la Nación: los Parques Nacionales en la Argentina en la primera mitad del siglo XX», Revista Europea de Estudios Latinoamericanos y del Caribe, N. ${ }^{0}$ 73, 2002, pp.5 21).
} 
(Buenos Aires, 1907-1909), Hotel Sierras (Alta Gracia, 1908), Hotel Casino Termas de Cacheuta (Cacheuta, 1910-1913), y el Hotel Continental (Empedrado, 1913).

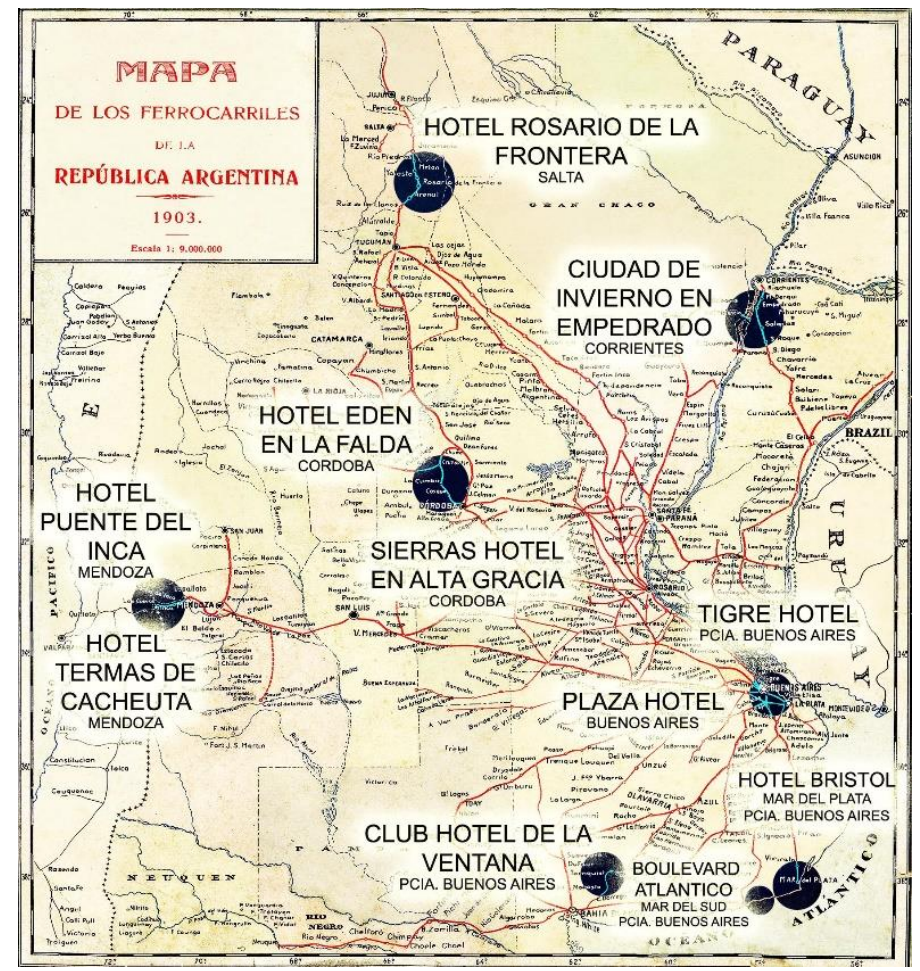

Figura 1. Localización de los GH en el territorio argentino. Elaboración propia sobre mapa de FFCC de Argentina. $A G N$, disponible en https://www.facebook.com/ArchivoGeneraldelaNacionArgentina/.

Esta primera enumeración permite observar varias cuestiones. Por un lado, que a pesar de encontrarse dentro de un arco temporal reconocido el de los grandes viajes de las élites locales a Europa, esto no significó el desinterés por las propuestas que iban naciendo en el territorio nacional, sino todo lo contrario. Como se aprecia en la prensa de la época, ver y ser visto en estos nuevos lugares de ocio distinguido pasó a ser parte de la sociabilidad obligada en este sector social. Desde ya, no son demasiados los establecimientos construidos que pueden ser considerados dentro de la categoría GH, dentro de la cual tomamos solo a aquellos que fueron concebidos como edificios cuya infraestructura garantizara su funcionamiento autónomo, y que además contaran con una imagen, comodidades y atributos que dieran cuenta del status de sus huéspedes. El número resultante se debió a que, como veremos a continuación, su desarrollo se apoyó casi exclusivamente a iniciativas privadas con recursos y alcances dispares.12

\footnotetext{
${ }^{12}$ La aparición de estos GH estuvo acompañada de otros proyectos hoteleros de menor escala, aunque algunos de ellos con la misma vocación de lujo, sobre todo en las capitales de provincia. Por una cuestión de espacio, no es posible desarrollarlos aquí.
} 
Por otro lado, la diversidad geográfica de emplazamientos de estos GH da cuenta de que el impacto de la llegada del turismo en la historia del entorno construido también fue muy variable. Si en el caso de Buenos Aires el Plaza Hotel vino a consolidar la modernidad de la ciudad con el desarrollo incipiente del área del Retiro -para entonces considerada casi suburbana pero próxima al centro neurálgico de la ciudad, el emplazamiento de los GH situados en parajes alejados solo fue factible a partir de la invención de una atractividad vinculada al territorio nacional y la posibilidad efectiva de acceder a ellos. En un período donde la avanzada inmigratoria pronto comenzó a considerarse una amenaza, es posible entender la utilización del turismo como una herramienta más para fortalecer el sentido identitario nacional, donde el desarrollo del ferrocarril se convierte en un factor indispensable. Se trata de un círculo virtuoso que comienza a desarrollarse de la mano de unos pocos pioneers, esto es, empresarios patriotas con visión de futuro. Tal como se menciona al comienzo de una nota sobre las bondades del balneario situado en Rosario de la Frontera en 1907:

... la variada naturaleza de nuestro país ofrece á millares los casos que podrían servir para convencer á los admiradores de lo exótico, de que no se necesita pasar la frontera ni cruzar el mar para ver bellezas y prodigios. Tenemos, dentro de los límites de la república, las llanuras, los ríos, las cataratas y las cimas que ó son las más grandes del mundo ó no desmerecen en la comparación [...] Lo único que nos falta es la presencia y la actividad del hombre en grado suficiente para sacar partido de todo eso y levantar al lado de la gran obra de la naturaleza las más grandes obras del esfuerzo humano. Algo se hizo en tal sentido, merced al espíritu de empresa que ahora se extiende por todas partes. Don Eduardo Abello es uno de los que con mayor entusiasmo han acometido la tarea: «Si un ferrocarril y un hotel», nos decía hace poco, «transformaron el Far West, iniciando el pujante desarrollo de esa parte del territorio yanqui, por qué no podríamos hacer lo mismo en tantos puntos de la Argentina dignos de suerte igual? Y sobre todo, ¿̇por qué no se han de acometer grandes empresas donde la gran facilidad del ferrocarril ha llegado como una tentadora invitación?».13

Tal como imaginaba el empresario entrevistado por Caras y Caretas, las funciones de traslado y alojamiento mejoraron taxativamente gracias al ferrocarril y al hotel. Sus virtudes se retroalimentaron y permitieron expandir el conocimiento del país y los negocios a él ligados. Como se destaca en la cita, ya no era necesario cruzar frontera alguna para encontrarse con maravillas y prodigios, había que descubrir lo

13 «Los grandes balnearios. Rosario de la Frontera», Caras y Caretas [Buenos Aires] N. ${ }^{\circ} 450$, mayo 18, 1907, p. 78. 
propio. No obstante, para abocarse a esta empresa era necesario contar con un capital económico y social destacado, por lo que fueron contados los hombres de empresa que se dedicaron a la promoción de estos nuevos espacios de disfrute. Dentro de este selecto grupo el nombre que se destaca es el de Ernesto Tornquist (1842-1908).

Tornquist fue parte de la élite nacional dentro del grupo que Leandro Losada denomina de «inmigrantes tempranos», esto es, familias que se asentaron en el país hasta mediados del siglo xIx y lograron incorporarse a la alta sociedad por vía de prosperidad económica o de matrimonio. Luego de cursar estudios en Alemania, aún muy joven se empleó en una empresa de capitales belgas que en 1873 pasó a sus manos con el nombre de Ernesto Tornquist y Compañía. A partir de entonces, la compañía creció al compás de los cambios productivos de la región pampeana. Tornquist fue, además, un hombre interesado en el desarrollo del país. En tanto amigo personal de los más importantes miembros de la política nacional, como Julio Argentino Roca y Carlos Pellegrini, incursionó en tareas diplomáticas como la negociación de la deuda nacional y la resolución del conflicto fronterizo con Chile. La diversificada agenda de inversiones del grupo Tornquist pronto se vio orientada a responder las demandas derivadas de la expansión económica de los sectores altos que comenzaban a canalizar localmente sus gastos suntuarios. Dentro de ellos, el de servicios hoteleros constituía un novedoso sector nacido en Europa a mediados del siglo XIX con la aparición suntuosos edificios en las principales capitales. Según indica Gilbert «estos reprodujeron la arquitectura de los grandes palacios de la aristocracia y se constituyeron en un indicador de estatus económico para la burguesía enriquecida por los cambios derivados de los procesos de industrialización» (123).

Las nuevas conductas de las clases acomodadas convergieron en el desarrollo urbano y turístico de Mar del Plata. La llegada del ferrocarril en 1886 fue el puntapié inicial para el florecimiento de nuevos emprendimientos asociados. Entre ellos, la relación personal de Tornquist con Pedro Luro dio impulso a la iniciativa conjunta para la construcción del Bristol Hotel a la manera de los grandes hoteles europeos. Tornquist, demostrando su compromiso con el proyecto, mandó además a construir una villa de verano para su familia, iniciando una tendencia entre la élite. Volviendo al hotel, si bien en un inicio sus instalaciones distaban de ser fastuosas, su visita poco a poco se fue instalando como un requerimiento insalvable de roce social entre las clases 
altas, haciendo del hotel «una escuela mundana».14 Esto impulsó la progresiva complejización del hotel hasta que finalmente en 1911 todas sus propiedades fueron adquiridas por una nueva sociedad incorporada al grupo Tornquist: la «Compañía Nacional de Grandes Hoteles», ${ }^{15}$ que reemplazó la construcción original por un imponente palacio inaugurado en 1912.

El otro GH construido por Tornquist fue el Plaza Hotel, ideado en 1907 e inaugurado en 1909 con vistas a los festejos del Centenario. El libro que funciona como presentación del hotel justificaba su construcción aduciendo que:

El crecimiento rápido de Buenos Aires hasta su actual extensión enorme y su población tan considerable, el número de personas que son atraídas a estas playas por intereses de viaje o de negocios, junto con el incremento de riqueza y la cultura social habían hecho sentir de algún tiempo a esta parte un vacío notable: la falta de un hotel digno, por su tamaño e instalación, de esta ciudad principal de Sudamérica, capital de un país, cuyo futuro es cada año más difícil de medir, por razón de su capacidad al parecer ilimitada de expansión y mejoramiento. La ciudad de Buenos Aires, llenándose constantemente de edificios públicos y mansiones particulares más y más suntuosos, aún carecía de un hotel que pudiera compararse con aquellos famosos de Londres, París o Nueva York, los que sobre enriquecer la parte arquitectónica de la ciudad, aumentan sus atractivos para residentes y forasteros, proveyendo a los gustos refinados de los más exigentes. A llenar este vacío se adelantó el argentino más emprendedor y patriótico de nuestros tiempos, el eminente financista Ernesto Tornquist (Q.E.P.D.). Con esa larga vista que lo caracterizaba, reconoció la necesidad para Buenos Aires de tal Hotel, que reúna el más estudiado confort con el mejor lujo. ${ }^{16}$

Así como el Bristol enseguida se asoció al ocio estival ostentoso, el Plaza Hotel fue sinónimo de lujo metropolitano, y por sus salones se paseaba la crème de la crème. Diarios y revistas de época muestran la agitada vida social que se daba cita en sus

\footnotetext{
${ }^{14}$ Como indican Pastoriza y Torre, el hotel ofreció a la alta sociedad no solo un espacio donde mirar y ser mirados, sino que también sirvió como un artefacto de iniciación a las formas del ocio distinguido (Elisa Pastoriza y Juan Carlos Torre, Mar del Plata: un sueño de los argentinos, Buenos Aires, Edhasa, 2019).

${ }^{15}$ La compañía había sido iniciada en 1888 por otros miembros de la élite -Carlos Pellegrini, Francisco Seeber, Vicente Casares, Saturnino Unzué, Eduardo Casey y Francisco Uriburu, Carlos de Mot y Antonio Marechal- con el fin de «comprar, edificar, arrendar y explotar hoteles destinados a viajeros en la capital federal y otros puntos de la República» (Compañía Nacional de Grandes Hoteles, Estatutos de la Compañía Nacional de Grandes Hoteles, Buenos Aires: Imprenta Coni é Hijos, 1888, p. 4) y se proponía iniciar sus acciones con la construcción de un gran hotel modelo en el centro de la ciudad de Buenos Aires, del cual no encontramos datos acerca de su efectiva concreción.
}

${ }_{16}$ Plaza Hotel, Plaza Hotel, 1909, s/p. 
lujosos interiores, recibiendo mandatarios extranjeros o grandes personalidades de la cultura. El rol de Buenos Aires como sinécdoque de un país moderno y cosmopolita en crecimiento requería de un hotel a la altura de estas circunstancias. En tal sentido, la construcción del Plaza no remitía simplemente a un negocio económico, sino que, como se destaca en el libro que acompañó su inauguración, era entendida como un acto patriótico de su creador.

La conciencia de Tornquist acerca de la importancia de generar estas empresas determinó su participación - en menor o mayor medida - en la construcción de varios de los GH que aquí se presentan. Así, además de los ya mencionados Bristol y Plaza, encontramos su nombre asociado a la construcción del Tigre Hotel, acompañado por Emilio Mitre y Luis García; el Hotel Edén, en cuyo proyecto actuó como financista, y el Hotel Club de la Ventana, donde colaboró como proveedor de materiales de construcción. Luego de su muerte, hacia 1914 su empresa también se hizo cargo del Hotel de Rosario de la Frontera.

Más allá de que aquí decidimos posar la mirada sobre Tornquist como ejemplo paradigmático de estos empresarios patrióticos, entre los directorios, fundadores, financistas y luego huéspedes de estos hoteles encontramos siempre los mismos apellidos. La heterogeneidad en los roles contrasta con la homogeneidad de un micromundo de placer creado por y para las élites. El acceso directo a espacios de poder permitía que los emprendimientos contaran con beneficios extraordinarios como la instalación de una parada específica del ferrocarril, facilidades de financiamiento y la publicidad asegurada de sus eventos de temporada. Al mismo tiempo, este cruce interpares permite mostrar de manera clara el grado de relación entre el desarrollo de los negocios, la incorporación de tecnología y la fuerza de los vínculos de la clase alta.

Como ejemplo más acabado de esta estrecha vinculación se destaca el Hotel Continental en Empedrado, Corrientes. Se trata de caso singular ya que el grandilocuente objetivo de su impulsor, Pedro Olegario Luro (hijo de Pedro Luro), con apoyo del gobierno provincial -que cedió las tierras a cambio de su urbanización-, era construir una completa «ciudad de invierno» para las élites porteñas en un lugar desconocido para ellas. Para ello, además del GH se proyectó una ciudad completa con puerto y estación del ferrocarril creados ad hoc que implicó una inversión multimillonaria y se promocionaba así: «La residencia invernal más bella y agradable 
de Sud América. Salud y bienestar. Temperatura ideal. Aire benéfico y saludable». ${ }^{17} \mathrm{La}$ inauguración, llevada a cabo los días 29 de junio de 1913, fue realizada con gran pompa y a ella asistió un buen número de familias de la élite (Domínguez 2007).
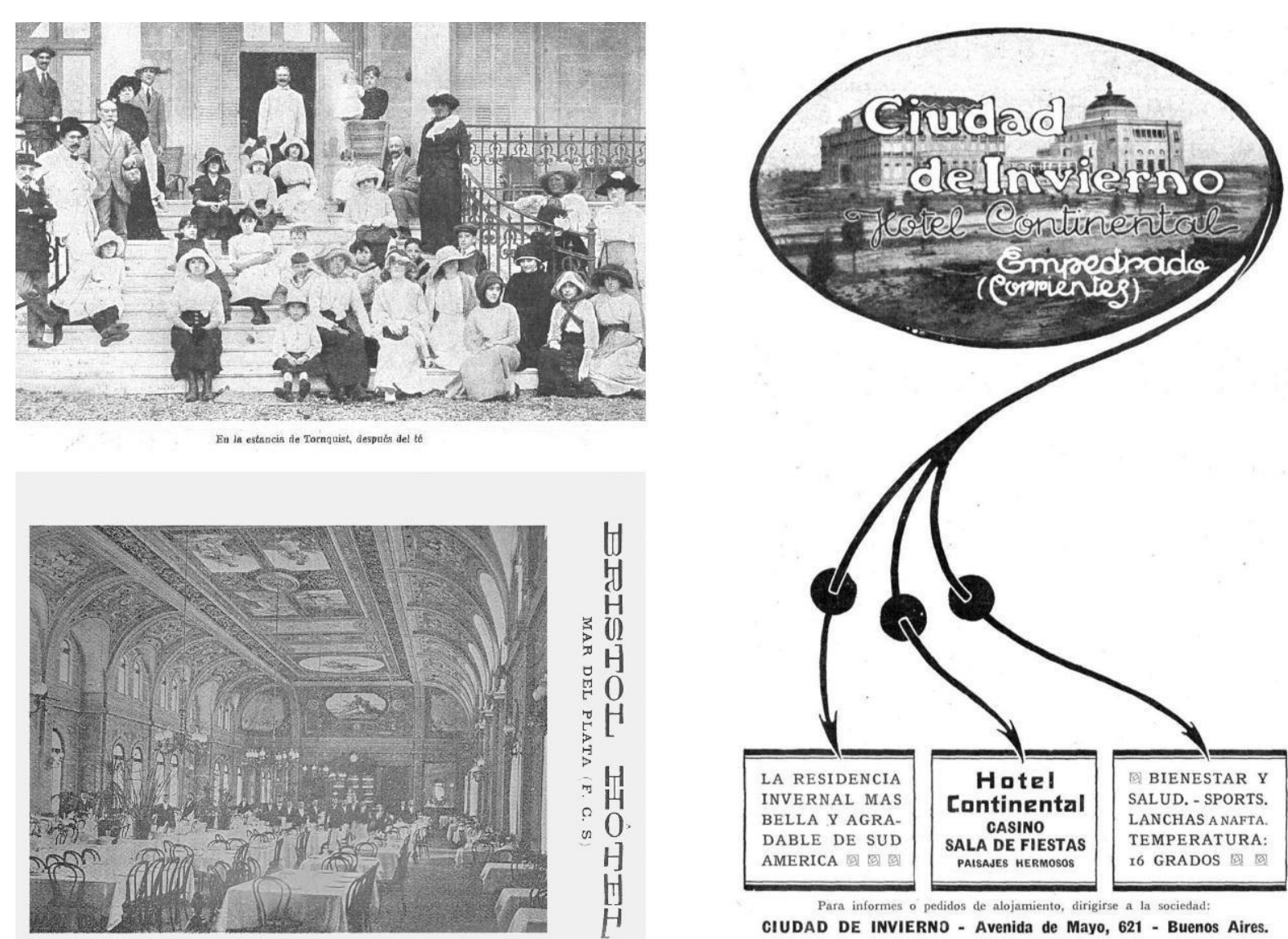

Figura 2 (Arriba izq.) Tornquist en su casa de veraneo en Sierra de la Ventana. Caras y Caretas 12/2/1912, p. 88.

Figura 3 (Abajo izq.) Comedor del Bristol Hotel. Guía Baedeker, 1907.

Figura 4 (Der.) Publicidad «ciudad de invierno» y su oferta turística. Caras y Caretas 12/7/1913, p. 11.

Por fuera de estos pioneers, en este período hubo otro agente en la construcción de GH: las empresas ferroviarias. El desarrollo del ferrocarril durante el último tercio del siglo XIX alentó a las empresas a crear instalaciones que sirvieran a los viajeros como lugares de descanso y de recreo. ${ }^{18}$ Este es el caso del Club Hotel de la Ventana, ideado por un grupo de hombres de la élite pero llevado adelante por la compañía

\footnotetext{
${ }_{17}$ Publicidad, Caras y Caretas, [Buenos Aires] N.$^{\circ} 769$, junio 28, 1913, s/p.

${ }^{18}$ Desde mediados del siglo XIx los ferrocarriles en Gran Bretaña se articularon con el desarrollo turístico de vastas zonas antes inaccesibles, construyendo hoteles en esos parajes. Esta experiencia resultaba un antecedente conocido para los dueños del BAP. De este modo, según Lacoste, cuando «llegaron con los rieles del ferrocarril trasandino al corazón de la cordillera de los Andes hacia el 1900, solo tenían que aplicar allí lo que habían realizado en Europa» (Pablo Lacoste, «El Ferrocarril Trasandino y la construcción de la cordillera como espacio social (1893-1947)», Entrepasados, N. ${ }^{\circ}$ 24-25, 2003, p. 180).
} 
británica Ferrocarril Central Sur, para lo cual creó en 1903 la estación Sauce Grande (actual estación Sierra de la Ventana) y un primer hotel a la salida de la estación para el alojamiento de los trabajadores. El complejo definitivo, construido entre 1904 y 1911, se hallaba a 550 metros del nivel del mar, a los pies de las sierras. Durante la fiesta inaugural fue definido por el general Roca como «la maravilla del siglo». Dada la gran envergadura de la obra, se contó incluso con la venia del gobierno provincial para la construcción de un trencito de trocha angosta que acercara a los huéspedes desde la estación hasta el hotel, dado que los pocos coches disponibles no daban abasto (Scandizzo 50-51).

Otro caso es el hotel del Puente del Inca, ubicado a los pies de la cordillera a 2700 metros de altura, posibilitado en este caso por la acción de la Compañía de Hoteles Sudamericanos perteneciente a la empresa británica Buenos Aires al Pacífico (BAP), dueña del Ferrocarril Transandino. Luego de la firma de los pactos de paz con Chile en 1902, la realización del túnel de la Cumbre y las vías férreas que se trazaron permitieron la explotación de un área antes solo accesible por tracción a sangre en un recorrido de dos días (Lacoste 2003). Incorporando la novedad del paisaje cordillerano al ya probadamente exitoso turismo termal, en 1913 «otra empresa subsidiaria FC BAP, levantó el formidable Hotel Termas de Cacheuta, el mayor hotel de turismo de la Argentina de su época, emplazado en el corazón de la cordillera de los Andes, a 1300 metros de altura y con una capacidad de 150 habitaciones». ${ }^{19}$

Tanto en el caso de Ventana como en los de Mendoza, cabe destacar que el hecho de que los constructores fueran las compañías ferroviarias no implicaba un tono distinto en cuanto al avance sobre un territorio a ser conquistado en conjunción con la búsqueda de lujo y distinción. En este sentido, en la mayoría de los casos aquí presentados la incorporación de nuevos paisajes significó un desafío en términos de infraestructuras y tecnologías que dieran cuenta del entorno, al tiempo que se imponían en él. El ferrocarril y el hotel fueron los elementos indispensables para el éxito de esta empresa, pero no suficientes. A continuación presentamos un abordaje de los GH en relación con algunos de los temas que los atravesaron, yendo desde lo específico del hotel -la habitación - hasta los aspectos más generales, como la

19 «Termas de Cacheuta. Gran Hotel Balneario Casino» en Revista mensual del BAP, N. ${ }^{\circ}$ 2, enero 1918, pp. 11-13. 
apropiación de la naturaleza en la oferta turística y la «maquinaria» necesaria para su subsistencia.

\section{Infraestructuras de confort: lo metropolitano en lo virgen, lo virgen en lo metropolitano}

Consideramos por lo ya dicho que los GH de fines del siglo XIX e inicios del XX se encontraban entre dos mundos: el de la naturaleza y el de la metrópolis. Una naturaleza virginal, necesaria como depuración de la vida metropolitana, que a su vez funcionaba como símbolo de salud -especialmente después de las epidemias de cólera y fiebre amarilla - y que asimismo habilitaba otro tipo de ocio, deportes y paseos vinculados a ese entorno. Y una metrópolis que se hacía presente en el confort que brindaban los edificios así como en las formas de sociabilidad, carnavales y popurrís, formas de divertimento de las élites en los ambientes «pintorescos». Esta categoría arquitectónica complementaba el estilo de vida urbano ostentoso con la introducción de tendencias «depuradas» en relación con el paisaje extraurbano. Así, los hoteles funcionaron como artefactos mediadores y posibilitadores de un tipo de veraneo que otorgaba importancia tanto al confort como a lo exótico, sentando un tipo de sociabilidad de clases altas en parajes naturales, llevando prácticas metropolitanas al territorio «virgen».

Situar al hotel como avanzada y centro de irradiación del emprendimiento turístico en territorios naturales se aleja de las formas en que tradicionalmente se analizó a estos complejos. Desde la mirada internacional diversos autores asociaron el desarrollo hotelero con la dinámica urbana. Según Daniel Boorstin ([1965] 2002), la construcción de hoteles en Estados Unidos desde 1830 en muchos casos había antecedido a las líneas férreas - caso opuesto al inglés-, buscando atraer colonos, negociantes y «toda la parafernalia de la grandeza metropolitana» (Boorstin [1965] 2002). ${ }^{20}$ Explica así que los hoteles solían ser confundidos con instituciones públicas

\footnotetext{
20 Según este autor «... en las ciudades emergentes de Occidente, el hotel, como el periódico, desempeñaba un papel que no podía ser imitado en el Viejo Mundo. [...] En Inglaterra, los hoteles de los ferrocarriles fueron los pioneros, pero en Estados Unidos los hoteles de primera clase aparecieron incluso antes del ferrocarril. De hecho, a menudo se construyeron con el propósito de atraer ferrocarriles, junto con colonos, periódicos, comerciantes, clientes, abogados, médicos, vendedores y toda la parafernalia de la grandeza metropolitana [...] los hoteles eran ridículamente desproporcionados con respecto a sus alrededores: fueron construidos no para servir a las ciudades sino para crearlas (Boorstin ([1965] 2002., pp. 182-183, traducción propia).
} 
por su escala y decoración. Andrew Sandoval-Strauz (2007) los analizó como parte de una red destinada al confort urbano, mientras que Nikolaus Pevsner (1980) desarrolló una línea tipológica de hoteles que dio por sentado al surgimiento del programa como demanda del crecimiento de las ciudades. Este hecho lo llevó a la comparación entre casos norteamericanos y europeos en términos de monumentalidad y sofisticación, obviando a los hoteles que no se adecuaran a sus variables de análisis. En ese sentido nos interesa poner de manifiesto la relevancia del grupo de $\mathrm{GH}$ seleccionados como centros concebidos en relación con la naturaleza, que se diferencian de los hoteles urbanos, por ejemplo, en su morfología: un hotel urbano tiene la tendencia a crecer en altura por la lógica de la densificación, mientras que los hoteles insertos en parajes naturales tienden a extenderse y dominar el territorio con ramblas, terrazas, miradores, galerías-solarium. Estos elementos pueden disociarse del hotel, buscando un mayor acercamiento al paisaje, como sucedió con las ramblas del Tigre Hotel o del Bristol en relación con el agua, o pueden incorporarse al edificio formando parte de su imagen, como se puede apreciar en el hotel de Rosario de la Frontera en Salta, o en los hoteles Edén y Sierras en Córdoba. Es decir, las posibilidades de ocio se adecúan a la oferta natural: las sierras, termas, playa o la montaña, permiten diversas formas de apropiación y disfrute; y los hoteles eran concebidos desde esas lógicas.

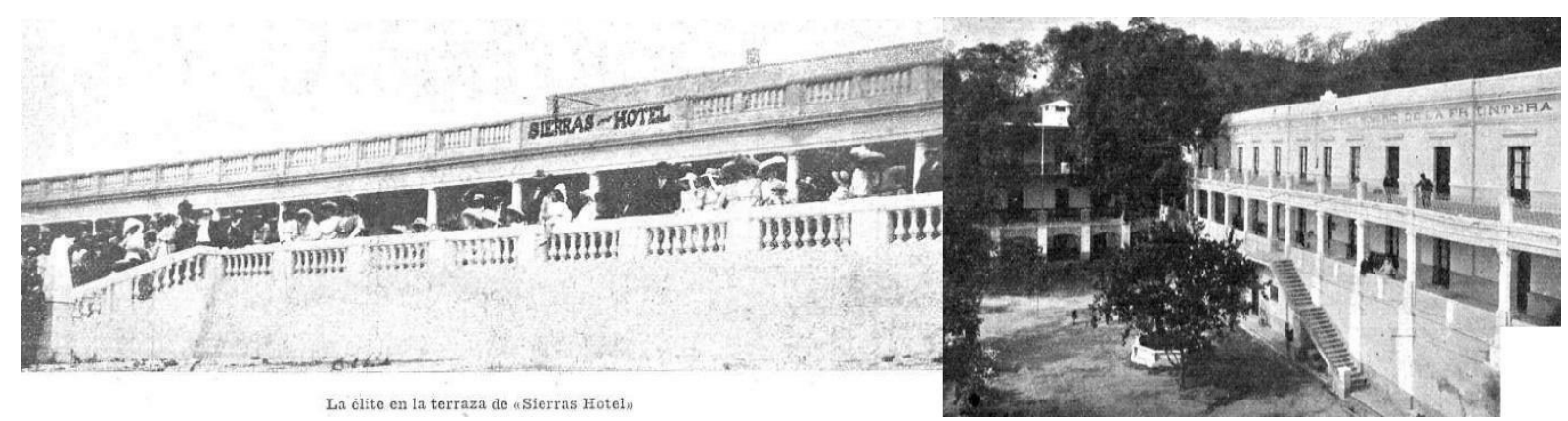

Figura 5 (Izq.). Hotel Sierras de alta Gracia. Caras y Caretas 8/1/1910, p. 16.

Figura 6 (Der.). Hotel Rosario de la Frontera. Caras y Caretas 28/11/1903, p. 47.

Entonces, un aspecto que resulta importante destacar es la relación que se establece entre el conjunto edilicio y el paraje natural, aquello que denominamos como la relación naturaleza-metrópolis. En torno a los balnearios de la costa atlántica resulta principal el caso del Hotel Bristol (1886). En la Guía del bañista editada por el hotel en 1887, aparece como justificación de la construcción del complejo las «condiciones de salubridad» que brinda el clima de Mar del Plata a los cuerpos: 
... Apartados de nuestras tareas ordinarias y en presencia de nuevos horizontes, se recrea, se alimenta, se baña el espíritu [...] en medio de esa calma absorbente, por la contemplación de aquellos grandiosos cuadros que se desarrollan al pasear de la vista por doquier, desde las orillas del grave y majestuoso Océano. En ese orden se persigue(n) [...] lugares más adecuados para tomar los baños, al menos establecimientos y sitios que ofrezcan más comodidad y decencia a los que a ellos concurran. ${ }^{21}$

Así, el hotel condensaba ambas experiencias: por un lado las ramblas y casillas de madera para uso de los bañistas, y por el otro el hotel como espacio de relax y confort. El crecimiento del conjunto fue exponencial. El hotel pasó de ocupar una manzana con un edificio de 67 habitaciones, a expandirse en 1890 hacia otra manzana contigua, que contenía comedores y salones para eventos, casino y jardines de esparcimiento. La ampliación se asentó como imagen del conjunto, mirando hacia la rambla y el mar, volcando un ostentoso lenguaje afrancesado en consonancia con el programa público del hotel. La imagen del edificio anexo no tiene ningún tipo de vínculo con la imagen del edificio original, que contiene las habitaciones y departamentos, como se aprecia en las figuras 7 y 8.

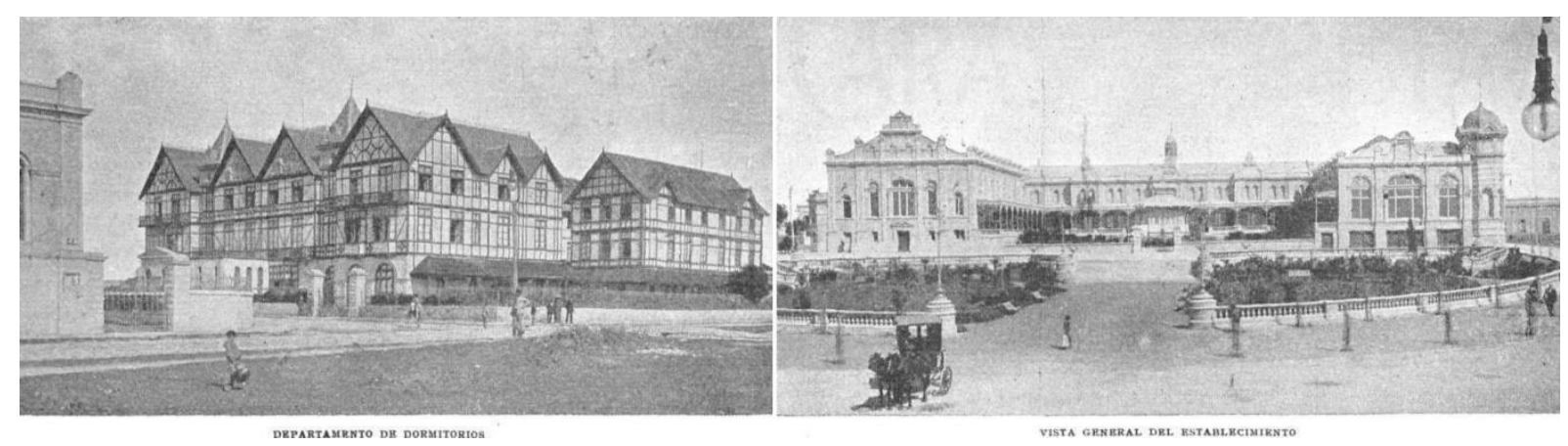

Hotel Bristol. Figura 7 (Izq.). Edificio de habitaciones y departamentos | Figura 8 (Der.). Edificio de comedores y programas públicos. Caras y Caretas 13/12/1902, p. 21.

La llegada del ferrocarril en 1886 desde Buenos Aires y las inversiones de Tornquist, como ya se advirtió, resultaron fundamentales para volver al Bristol un centro de referencia de otras instalaciones: nuevos hoteles, clubes y asociaciones guiaban a los turistas en sus propagandas en relación con su cercanía con la rambla o el hotel. ${ }^{22}$ Caras y Caretas en 1899 señalaba que «Mar del Plata, con sus grandes y

\footnotetext{
${ }^{21}$ Bristol Hotel, Guía del bañista, Buenos Aires, J. H. Kidd y Cía, 1887, pp. 9-10.

${ }^{22}$ A partir del desarrollo del Hotel Bristol surgieron distintas asociaciones y clubes, como el Pigeon Club en el actual Torreón del monje (1904), el Golf Club (1896), el Club Mar del Plata (1908) y el más exclusivo Ocean Club (1912), que organizaban eventos y fomentaban el crecimiento de la ciudad y su turismo. Por ejemplo, en la publicidad del Confortable Hotel en Mar del Plata en Caras y Caretas se sitúa su
} 
confortables hoteles, con su vida de elegantes frivolidades y de aristocráticos refinamientos es sin duda un exponente, una alta expresión de nuestra cultura de nuestra sociabilidad adelantada, que viene a completarle a Buenos Aires su fisonomía de gran ciudad».23 La ciudad-balneario se había consolidado como un centro de avanzada de la metrópolis sobre el mar, y el hotel se había instalado como referencia de ese estilo de vida. De esta imagen se tomó Mar del Sud para construir el Hotel Boulevard Atlántico (1889). Su finalidad era la de construir un balneario municipal y, como el Bristol, contó con instalaciones de confort. Sin embargo, el emprendimiento no prosperó debido a que el ferrocarril nunca llegó por la crisis económica de 1890, cerrando definitivamente sus puertas un año más tarde.

Un caso diferente en cuanto a la relación naturaleza-metrópolis se planteó con el Tigre Hotel (1890), ya que su cercanía a Buenos Aires transformó al delta en un lugar elegido para escapadas cortas. James Scobie (1986) señala que antes de la fiebre amarilla ya existían casas de familias inglesas que, siguiendo la línea del ferrocarril, dieron paso a la creación de algunas localidades. Podemos asumir que la imagen del hotel sintonizaba con las estéticas nórdicas de los cottages aledaños. El edificio se inauguró en un momento de intenso desarrollo del municipio, con el crecimiento del «Puerto de frutos» y la migración de las regatas - deporte popular entre los ingleses, del riachuelo hacia el río Luján. El edificio se ubicó en el cruce de los ríos Luján y Tigre, aislado del casco urbano y construyendo una nueva centralidad basada en las actividades deportivas y de ocio (fig. 9 y 10). Su estructura contaba con tres pisos y 120 habitaciones, un mirador de remate superior, salones para fumadores, billar, un gran comedor y espacio para el casino. Las áreas recreativas, además de la rambla para ver las regatas, se destinaban al cricket, canchas de tenis y pistas de patinaje. Con el tiempo se incluyó un patio andaluz, jardines de invierno y un garaje. El Club Tigre (1912) fue construido por la iniciativa de los vecinos en el predio lindero al hotel, y tuvo el objetivo de complementar sus actividades sociales y deportivas. El éxito de estas infraestructuras fue tal que, aun cuando en 1944 se produjo el cierre y demolición del hotel, la ciudad quedaría en adelante vinculada a un imaginario de ocio de fines de

localización «a tres cuadras de la playa del Bristol» (Caras y Caretas, [Buenos Aires] N. ${ }^{\circ}$ 66, ene 6, 1900, p. 14)

23 «Mar del Plata», Caras y Caretas [Buenos Aires] N. ${ }^{\circ}$ 21, febrero 25, 1899, p. 16. 
semana que había surgido en torno al edificio, a las actividades náuticas, y a su cercanía a la capital.

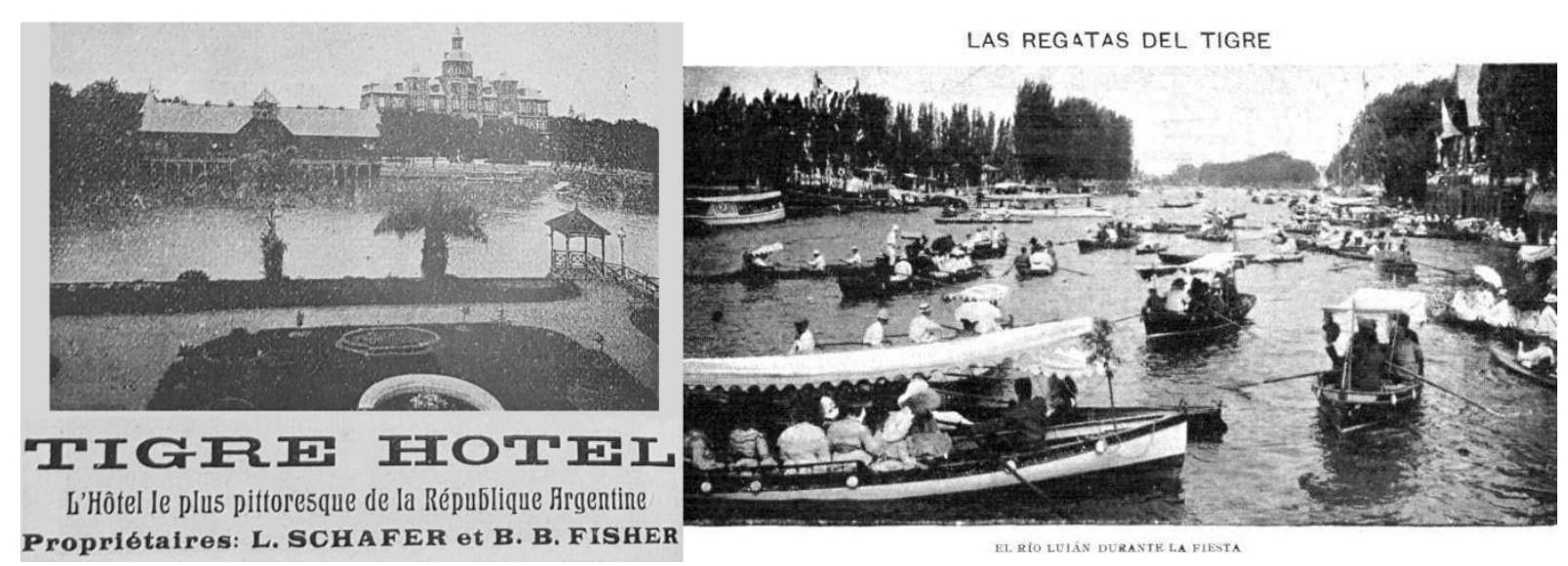

Tigre Hotel. Figura 9 (Izq.). Guía Baedeker, 1907 | Figura 10 (Der.). Regatas. Caras y Caretas 21/11/1903, p. 21.

Para aquellos hoteles localizados en el interior del país se pueden identificar ciertos rasgos compartidos, tendientes a funcionar como avanzadas de civilización en ámbitos naturales asociados a la salubridad. Por las largas estadías que demandaban las enfermedades, el turismo vacacional se sumó a la opción curativa. Estas necesidades son las que justifican la localización de varios GH: los beneficios del aire de las sierras para los hoteles Edén, Sierras Hotel en Córdoba y el Club Hotel de la Ventana en la provincia de Buenos Aires; las cualidades de las termas para los hoteles de Rosario de la Frontera en Salta y los de Puente del Inca y Cacheuta en Mendoza; y el suave clima templado para el Hotel Continental en Corrientes. Respecto a las comodidades, el confort y el lujo se asociaban a los beneficios de sanidad, transformando al reposo hospitalario en un momento de ocio.

Estos edificios contaron con una cantidad de habitaciones que oscilaba entre setenta y doscientas. ${ }^{24}$ No obstante, en su mayoría alcanzaron estas cantidades con el desarrollo del emprendimiento en el tiempo. El hotel Edén, por ejemplo, comenzó a funcionar con parte del edificio en construcción, mientras que el hotel de Rosario de la Frontera continuaría sumando habitaciones hasta la década del cuarenta (Marrey 1214). La disparidad de los conjuntos en relación con las habitaciones, no obstante, se encontraba en sus características de confort. No era lo mismo albergarse en una habitación del hotel Rosario de la Frontera, Edén o Sierras, que contaban con una

${ }_{24}$ Termas Hotel Puente del Inca, 70 habitaciones; Hotel Edén, 100 habitaciones; Sierras Hotel, 120 habitaciones; Hotel Termas de Cacheuta, 150 habitaciones, Club Hotel de la Ventana, 173 habitaciones, Hotel Continental y Hotel Termas de Rosario de la Frontera, 200 habitaciones. 
expansión directa al paisaje (fig. 11); a alojarse en el hotel Continental, núcleo de una «ciudad de invierno» (fig. 4). Otro tanto podemos decir respecto a los mendocinos, donde parte de las temporadas y la ubicación de los hoteles obligaban a priorizar otro tipo de comodidades asociadas al frío.
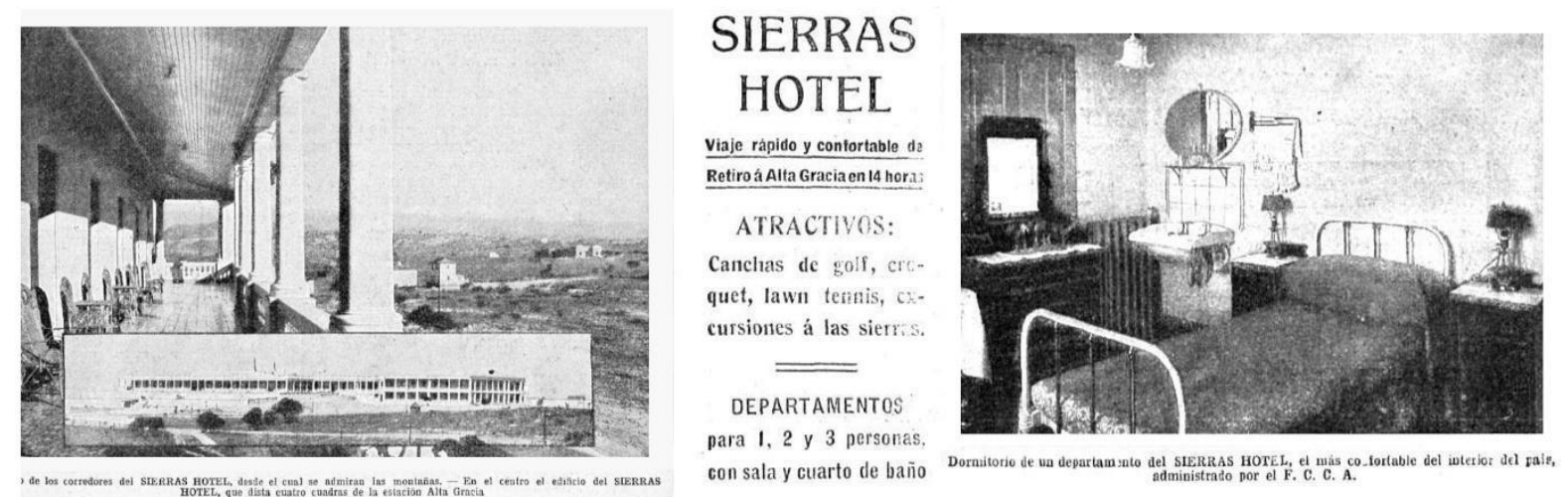

Hotel Sierras de Córdoba. Figura 11 (Izq.) y Figura 12 (Der). Caras y Caretas 11/11/1911, pp. $20-21$.

Asimismo, el confort de las habitaciones aparecía asociado en las publicidades a la higiene personal. En el Sierras Hotel, la habitación incluía un lavabo al lado de la cama (fig. 12). Esto resultaba fundamental, si tenemos en cuenta que el Edén contaba con ocho baños, o que en el hotel de la Ventana los 58 baños se compartían entre las 173 habitaciones. Una publicidad del Hotel de Rosario de la Frontera afirmaba que «cada baño tiene su antesala y su toilette (w.c.) con todos los perfeccionamientos sanitarios modernos»,25 aunque no se esclarecía si cada habitación contaba con un baño propio.

Por otro lado, como ya había dejado asentada la experiencia del Bristol, dentro del programa de los GH resultaban fundamentales los salones, casinos, salas para fumadores, invernaderos y cualquier otro espacio público para socializar entre los huéspedes. No obstante, representaban un inconveniente cuando el turista buscaba espacios de paz y silencio para relajarse. Así, en la planta del Edén (fig. 13) podemos ver la centralidad que ocupaba el comedor, los salones anexos que lo rodean, y habitaciones volcadas hacia el perímetro. La compacidad de la planta podía tener aparejado el problema acústico de los usos contiguos. Mientras que el Hotel de la

\footnotetext{
${ }^{25}$ Publicidad Hotel Rosario de la Frontera, Caras y Caretas, [Buenos Aires] N. ${ }^{\circ}$ 500, mayo 2, 1908, p. 17.
} 
Ventana destinó un lateral y el centro del trazado para albergar la parte pública del programa (fig. 14).

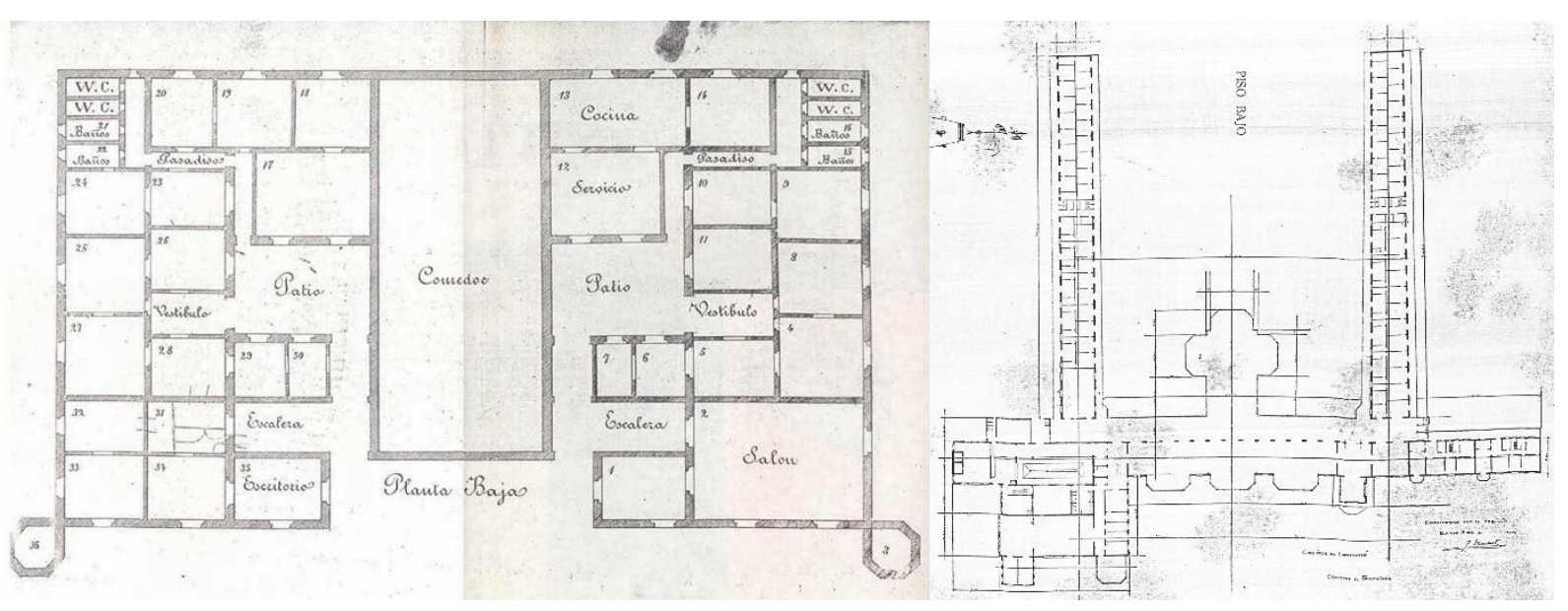

Figura 13 (Izq.). Hotel Edén en Córdoba. Planta baja. Edén Hotel La Falda, https://www.facebook.com/hoteledenlafalda/.

Figura 14 (Der.). Club Hotel de la Ventana. Planta baja, primer piso y vista general. Dunant y Mallet, 1913, pp. 28-29.

Por su parte, el hotel Continental destinó dos volúmenes separados, uno para las habitaciones y otro para el conjunto de casino, confitería y teatro, unidos mediante un «jardín de invierno» (fig. 4). En Cacheuta el programa se separó en diferentes niveles, a los que se accedía por medio de ascensores. Lo interesante de las distintas soluciones es que la extensión del territorio permitió localizar las partes del programa alejadas entre sí.

Entre los programas de ocio de los hoteles, ${ }^{26}$ además de los salones y comedores, se pueden diferenciar a aquellos que se destinaban a espacios termales, de los que solamente ofrecían el disfrute de los parajes naturales. Los primeros parecían disputarse la cantidad y calidad de las diferentes aguas, según sus composiciones químicas. En Rosario de la Frontera se contabilizaban nueve tipos, mientras que en Puente del Inca, pese a ser solo cuatro, se publicitaban como mejores que las aguas termales de Vichy «pues enfermedades que no han cedido con el uso de las aguas de Vichy, en pocos meses han desaparecido completamente con las de Mendoza»27. En

\footnotetext{
${ }^{26}$ Por ejemplo, el Club Hotel Sierra de la Ventana contaba con canchas de golf, polo, futbol, hipismo y pileta de natación, mientras que en Hotel Continental las actividades deportivas incluían un hipódromo, cancha de cricket, golf, tenis y fútbol.

${ }^{27}$ Revista Mensual del BAP, N. ${ }^{\circ}$ 2, [Buenos Aires] enero 1918, p. 34.
} 
este hotel las instalaciones termales se hallaban vinculadas a las del hotel, mientras que en el de Cacheuta:

El departamento de baños termales lo constituye una gran galería de mas de 100 metros de largo, donde están encerrados los preciosos manantiales de estas aguas [...] tiene 50 cabinas o cuartos de baño con su pileta o su bañadera correspondiente, su cama de descanso, etc... tiene salas de duchas y masajes con instalaciones ultra modernas [...] Además posee lo que se puede llamar una joya en toda América, esto es, un «emanatorio» cavado en la misma roca, donde se aspira las emanaciones del vapor producido, al surgir la tierra, por las aguas termales clasificadas como las más radioactivas del mundo ${ }^{28}$

Otro aspecto que destacamos en la construcción de los GH es su importancia como infraestructuras. Nos referimos con esto a la necesidad de funcionamiento del complejo de manera continua, en un contexto no siempre favorable, a veces alejados de las comunicaciones del ferrocarril, y con la necesidad de garantizar sus instalaciones especialmente durante las temporadas altas. Para ello contaban con maquinarias de producción y materias primas, así como precisaban de personal permanente para ocuparse de la atención al público y del mantenimiento general. Todos los GH contaban con infraestructuras para la generación de servicios. En los situados zonas montañosas, las tomas de agua resultaban una dificultad mayor, necesitando de tanques-cisternas para cubrir las grandes distancias desde el origen de la toma hasta el hotel. Las usinas eléctricas propias resultaban fundamentales para mantener los alimentos en las cámaras frigoríficas, para el funcionamiento de la comunicación telefónica, y para brindar electricidad al complejo. Las cocinas, organizadas por chefs de renombre, contenían diversos hornos (para producción de pan, de spiedo, etc.), panadería, maquinarias de producción de cerveza y fábricas de pastas (los dos últimos se encontraban en el hotel de Sierra de la Ventana). Granjas, huertas, molino harinero, caballerizas, mataderos, tambos, espacios para herrería y carpintería, solían localizarse alejados del hotel. Por otro lado, la categoría y complejidad de los emprendimientos requería no solo de grandes salones de eventos, sino también de estacionamientos, enfermerías y hasta peluquerías. Asegurar el funcionamiento y el nivel de las instalaciones demandaba grandes inversiones, y aun así el éxito del negocio no estaba garantizado.

${ }^{28}$ Ibídem, p. 13. 
Hemos observado que los emprendimientos corrieron con una suerte muy dispar, y que el involucramiento de empresarios de la élite o la elección de un entorno atractivo no implicaba un resultado asegurado. De esto da cuenta la corta vida del Hotel Boulevard Atlántico por la falta de acceso, del Hotel Club de la Ventana (cerrado en 1917 a raíz de la estatización del juego) y, aún más abrupta, la del Hotel Continental en Empedrado, cerrado a los dos meses de su inauguración por falta de fondos. La naturaleza tampoco estuvo ausente en las posibilidades de éxito o fracaso; los hoteles mendocinos sufrieron en varias ocasiones las severas consecuencias de diversos aludes. Por esto consideramos que los GH no representaban un negocio enteramente fiable, sino más bien un gesto de avanzada en territorios indómitos, una domesticación de la naturaleza que, en caso de ser exitosos, se desarrollarían como villas turísticas. Las figuras 15 y 16 de implantación de la Ciudad de Invierno y Sierra de la Ventana dan cuenta de ello: el hotel era planificado como centro condensador de producción y servicios a nivel territorial, y de su subsistencia dependía la suerte de cientos de empleados.
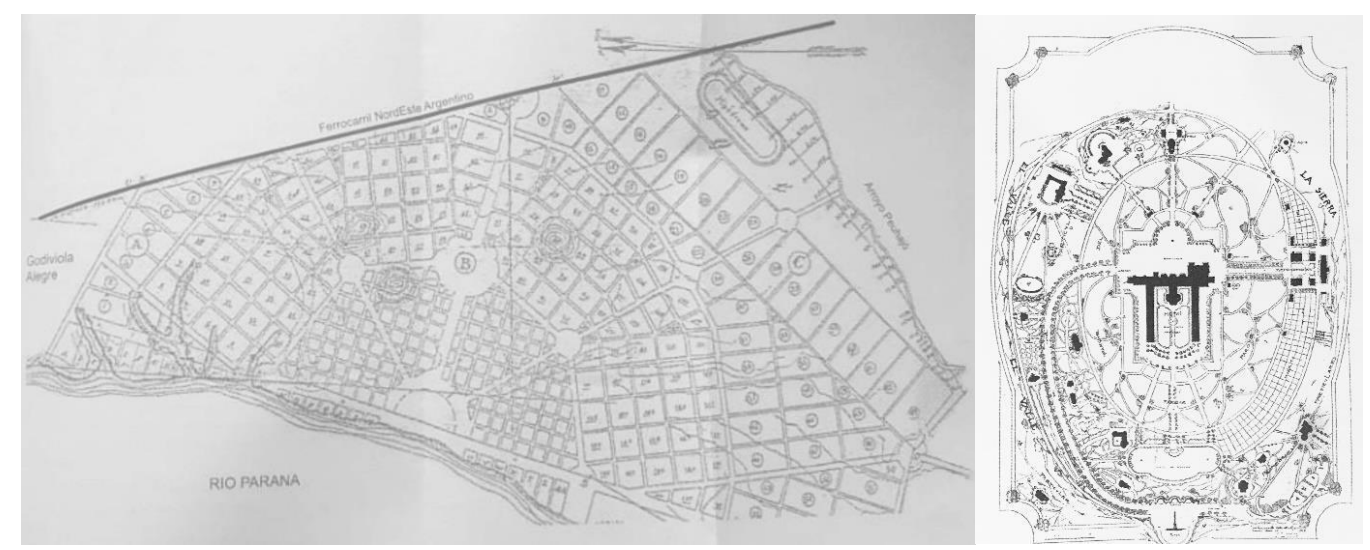

Figura 15 (Izq.). Implantación Ciudad de Invierno en Empedrado. Domínguez, 2007, s/n. Figura 16 (Der.). Implantación Hotel Club de la Ventana (Gutiérrez 2011 82)

Esta búsqueda de centralidad remite a la necesidad de reforzar la inversión económica puesta en el conjunto. En Mendoza, antes de construir el Hotel Termas de Cacheuta, una propaganda en 1913 mostraba las intenciones de consolidar una villa turística utilizando al hotel como garantía del emprendimiento:

... los lotes que vendemos tienen agua propia, que nace y muere dentro de la propiedad, de la cual se extrae el agua mineral Stalli, bien conocida en nuestros círculos comerciales. El suelo es verdaderamente prodigioso. Los cultivos que existen en los alrededores, las huertas, sobre todo, prueban este aserto [...] La propiedad principia sobre la misma Estación, en donde el terreno no vale menos de \$9,50 y \$10 el metro cuadrado [...] 
abarcando el conjunto la zona más rica, más pintoresca y más sana del valle. El terreno es seco, alto y se presta a la maravilla para chalets, quintas, casas de veraneo, etc. Un dato importante. Dentro de los mismos terrenos, de acuerdo con los planos respectivos, se empezará a construir en breve, el grandioso Nuevo Hotel, uno de los establecimientos termales de mayor importancia en la República. [...] Potrerillos dista diez kilómetros (diez minutos) del balneario de Cacheuta, y lo aventaja en comodidades, en panorama, en clima y posee tan buenas aguas como las famosas de aquellas termas. Para las familias, para los empleados, para los hombres de negocios: la propiedad está al alcance de todos. ${ }^{29}$

Finalmente, el caso del Plaza Hotel en la ciudad de Buenos Aires parecería desentonar con el conjunto de GH; sin embargo lo consideramos un caso modelo de infraestructura hotelera en una ciudad que se encontraba creando su identidad en un contexto de construcción de una imagen nacional. En tal sentido, la elección de Alfred Zucker como responsable para su construcción muestra una clara intencionalidad cosmopolita. Este arquitecto alemán trabajó en EEUU antes de venir a Buenos Aires y allí desarrolló varios hoteles, el Majestic, Hoffman, y Bolkenay, entre otras construcciones relevantes. ${ }^{0}$ Esta trayectoria se pone en línea con las aspiraciones locales que buscaban construir una ciudad moderna imaginada de acuerdo a las novedades que llegaban principalmente de la nueva meca de la innovación: Estados Unidos. De cara a los festejos del Centenario, se buscó desarrollar una imagen urbana que mostrara a la capital nacional como un destino de lujo para los visitantes extranjeros (González Bracco 2018). La elección para el emplazamiento del Plaza Hotel en una zona donde las élites también construían sus residencias permitió reforzar dicha imagen. Como indica Virginia Bonicatto (2011), la idea de un hotel de lujo para la ciudad no era nueva, pues desde 1906 funcionaba ya el Hotel Palace y en 1909 se inauguró el Hotel Majestic. No obstante, la singularidad del Plaza estuvo dada por los adelantos de confort y por una volumetría de vanguardia, dado que sus 9 pisos y 63 metros de altura lo convirtieron en el primer rascacielos porteño. Respecto a las comodidades,

... sistemas de transmisión de correspondencia por tubos neumáticos, teléfono, generadores eléctricos, agua fría y caliente, sistema de calefacción central, refrigeradores, vacuum de limpieza, etcétera, completaban la idea de «confort» y transformaban al edificio en una caja de sorpresas modernas. Como un oasis en el caos metropolitano, el Hotel

\footnotetext{
29 Publicidad, Caras y Caretas, [Buenos Aires] N. ${ }^{\circ} 755$, marzo 22, 1913, s/n.

${ }^{30}$ Revista de Arquitectura, [Buenos Aires] N. . 88, agosto 15, 1913.
} 
garantizaba la «comodidad y bienestar de los huéspedes» quienes podían descansar de la agitada vida metropolitana (Bonicatto 84-85).

Este juego entre el aislamiento y la integración con la ciudad se escenificaba en sus interiores. Las decoraciones de los salones principales se correspondían con la sofisticación de los palacios urbanos, mientras que algunos locales destinados al descanso o los negocios, como el café, contaban con estéticas más depuradas (figs. 18 y 19). Un espacio particular es la llamada «rotisería», con acceso desde el hotel pero también desde el exterior, pensado para reuniones de hombres de negocios de la ciudad, o para aquellos que desearan servirse de un lunch sin el protocolo de la etiqueta. La ecléctica composición espacial contribuía a destacar la heterogénea oferta de actividades que ofrecía el hotel, que buscaba convocar no solo al turista que llegaba a la ciudad sino también a personalidades y autoridades locales como ámbito para hacer negocios.

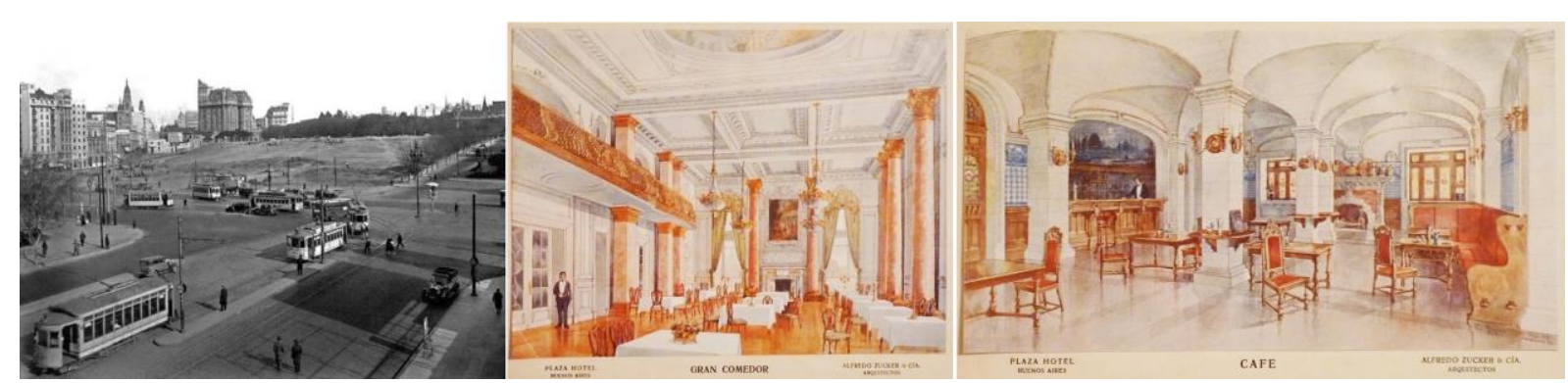

Plaza Hotel. Figuras 17 a 19 . Imagen general en 1920,31 croquis de salón principal y Café. Plaza Hotel, $1909, \mathrm{~s} / \mathrm{p}$.

Su implantación en un extremo de la ciudad aún poco urbanizado lo hermana con los otros GH en su vocación de crear nuevas centralidades (fig. 17). Asimismo, y a pesar de su emplazamiento urbano, el análisis hecho da cuenta de que el propio edificio funcionaba como artefacto mediador con el exterior, aunque en este caso el reparo fuera no ya de las inclemencias de la naturaleza sino de la «agitada vida metropolitana».

\section{Conclusiones preliminares}

La indagación sobre los GH en relación con sus condiciones de surgimiento y mantenimiento permiten observar algunos temas en común. En principio, la instalación de estos complejos artefactos como formas de construir nuevas

${ }^{31}$ Disponible en shorturl.at/fgzL2. 
centralidades en diversos territorios. Centralidades entendidas por un lado como conquista de la técnica sobre tierras vírgenes, en espacios muchas veces inaccesibles y contando con limitaciones geográficas, demográficas y climáticas para sus realizaciones, posibles gracias a los ferrocarriles. La nueva mirada que se construye sobre el territorio es estética, pero también -como se observó en la cita sobre Rosario de la Frontera - tiene una gran impronta nacionalista. En tal sentido, es de destacar que la mirada patriótica - que muchas veces se destaca como propia de las décadas siguientes- ya existía de una manera marcada. Aun antes de que el Estado comenzara a desarrollar una política turística, los pioneers y sus socios locales daban cuenta de esta suerte de conquista del desierto por otros medios, transformando los territorios vacíos o peligrosos en lugares para el disfrute de un nuevo tipo de ocio, plasmado en la sofisticación de los usos y costumbres que, gracias al desarrollo de los GH, comenzaron a asociarse al veraneo.

Esto explica que gran parte de estos emprendimientos tuvieran la misma impronta: ser el centro de nuevas villas turísticas. Mientras el Bristol se transformaba en punto de referencia de la creciente Mar del Plata, el Hotel de la Ventana vendió tierras periféricas a privados para la construcción de casas particulares de veraneo, los hoteles de Mendoza dieron inicio a poblados permanentes y la Ciudad de Invierno quiso ser punta de lanza de toda una empresa donde el estado provincial intervino tempranamente.

Pero también la centralidad implicaba el traslado de ciertas prácticas culturales. El Plaza, el Bristol y el Tigre fueron producto de la instalación de un modo de vida de clases altas donde ya había preexistencias, sea por asentarse en ciudades, por el tipo de turismo costero o por las actividades deportivas de remo. Sin embargo, la instalación de los GH incitó a una construcción y valoración de esos paisajes, cuya justificación última parece encontrarse en las formas de sociabilidad que allí se daban. Ocio natural, con deportes y paseos que explotaban las capacidades de la naturaleza; sumado al ocio propio de la lógica hotelera, que ofrecía instalaciones para casinos, banquetes, kermeses y fiestas con cotillones. De este modo, los $\mathrm{GH}$ formaron parte $-\mathrm{y}$ fueron expresión- de un momento en el cual las élites se sofisticaron, reformulando sus formas de ocio y sociabilidad. El lenguaje de estos edificios, entonces, debió representar y dar cuenta de estos refinamientos en un doble juego. Por un lado, al priorizar en las composiciones exteriores tradicionales que oscilaban entre la figura del 
palacio decimonónico y las composiciones no tan ortodoxas del pintoresquismo, surgía un lenguaje arquitectónico original vinculado al ocio. Por otro lado, los interiores mantenían motivos más tradicionales, lo que permitía comparar a estos GH con el lujo de sus equivalentes en Europa.

Sin embargo, fue en su funcionamiento como infraestructuras implantadas en territorios alejados donde se pudieron detectar los mayores conflictos, ya que la oferta turística debió complementar el ocio y la sofisticación para la temporada estival, con temas relacionados con su subsistencia durante todo el año. La distancia de los emprendimientos en relación con las redes de comunicaciones, la provisión de servicios esenciales y la garantía de alimentos resultaban indispensables; así como también la cantidad de personal necesaria para el mantenimiento de las instalaciones y de sus actividades. Este backstage en algunos casos, como en Edén o Sierra de la Ventana, se ubicaba en las periferias, alejado de los lugares y visuales privilegiados para las élites. Pero sin duda contribuyeron a la vocación de instalar una nueva centralidad.

Pese a que los GH que se citaban como inspiraciones ideales para pensar los casos locales se encontraban en Europa, también podemos ubicar al Hotel Bristol como el caso de referencia nacional. Las decoraciones, el confort, los salones y su oferta de variadas actividades, se instalaron en el imaginario de las clases altas y de los emprendedores hoteleros. No obstante, aunque el Bristol funcionara como modelo cultural, cada GH buscó diferenciarse de los demás desde la oferta particular que se apoyaba en lo singular de su paisaje y sus posibles actividades asociadas. La construcción como paisaje de diversos espacios antes considerados vacíos o peligrosos permitió la emergencia de un nuevo repertorio de lugares a descubrir y actividades a realizar: en el mar y el río: baños de sol, natación y deportes náuticos; en las sierras y montañas: caminatas saludables en medio del aire puro, fueron los motorizadores de un nuevo tipo de avanzadas de la civilización sobre el territorio nacional. Un delicado balance entrelazaba la singularidad del paisaje con el lujo interior que prometía lo mejor en cuanto a confort, tecnología y una estética distinguida y apropiada para las formas de sociabilidad de las élites. Estos elementos eran resaltados como los valores principales de los $\mathrm{GH}$, como puede observarse en las publicidades que acompañaron las inauguraciones y su posterior desarrollo. 
Por último, este trabajo también permitió observar tanto las consecuencias materiales de la implantación de varios de estos GH - hemos mencionado la creación de villas turísticas y nuevos asentamientos - como simbólicas, instalando muy tempranamente la idea de que era posible contar con un espacio local, singularizado por sus características paisajísticas e higiénicas pero también por sus atractivos de modernidad metropolitana, para ser utilizado en pos del descanso y la recreación. Posteriormente a nuestro período de análisis, la tipología GH continuaría su crecimiento, si bien el fenómeno de la escalonada masificación del turismo abrió las puertas a otro tipo de hotelería en donde entraron a jugar fuertemente nuevos actores, como el Estado nacional y los sindicatos.

\section{Obras citadas}

\section{Fuentes}

Bristol Hotel, Guía del bañista, Buenos Aires, J. H. Kidd y Cía, 1887.

Caras y caretas, varias ediciones [Buenos Aires, 1898-1914]

Compañía Nacional de Grandes Hoteles, Estatutos de la Compañía Nacional de Grandes Hoteles, Buenos Aires, Imprenta Coni é Hijos, 1888.

Plaza Hotel, Plaza Hotel, Buenos Aires, Ed. Ortega \& Radaelli, 1909.

Revista Mensual del bap, N. ${ }^{\circ}$, Buenos Aires, enero de 1918.

Revista de Arquitectura, N. ${ }^{\circ}$ 88, Buenos Aires, agosto 15, 1913.

Martínez, Alberto, Baedeker de la Republique Argentine [3. ${ }^{\text {a }}$ edición], Barcelona, A. López Robert, 1907.

---- Baedeker of the Argentine Republic [4. ${ }^{\mathrm{a}}$ edición], Barcelona, R. Sopena, 1914 .

Huret, Jules, De Buenos Aires al Gran Chaco, Buenos Aires, Hyspamérica, 1986 [1911].

- - - - «La sociedad argentina», Caras y Caretas [Buenos Aires] N. ${ }^{\circ}$ 750, febrero 15,1913, p. 65.

\section{Bibliografía}

Bonicatto, Virginia, Escribir en el cielo: relatos sobre los primeros rascacielos en Buenos Aires, Tesis mhcac, Buenos Aires, utdt, 2011.

Boorstin, Daniel, The Americans: The National Experience, NuevaYork, Rosetta Books, [1965] 2002.

Bruno, Perla, «Los hoteles de turismo (1930-1955): piezas claves del territorio turístico de la Argentina», Registros, Año 8, N. ${ }^{\circ}$ 9, 2012, pp. 54-80. Disponible en: https://revistasfaud.mdp.edu.ar/registros/article/view/84.

Corbin, Alain, El territorio del vacío. Occidente y la invención de la playa (1750-1840), Barcelona, Grijalbo-Mondadori, 1993. 
De Toni, Juan Pablo, Eden Hotel. El nacimiento de un pueblo, Córdoba, Editorial eh, 2007.

Domínguez, Alberto, La ciudad de invierno. Un símbolo de la belle époque, Corrientes, Moglia Ediciones, 2007.

Gilbert, Jorge, «Ernesto Tornquist, el organizador de un poderoso holding», en: Acuña, María y Tornquist, Luis Fernando (comps.), Aportes de un emprendedor de avanzada. Ernesto Tornquist cien años después. 1842-1908, Buenos Aires, Fundación Victoria Ocampo, 2011.

González Bracco, Mercedes, Entre relatos, imágenes y filmes: la construcción de la imagen turística de Buenos Aires, tesis mhcac, Buenos Aires, utdt, 2018.

Gutiérrez, Ramón (coord.), Manifestaciones francesas en la Argentina. PaquinDunant-Mallet-Flores Pirán-Ramos Correas, Buenos Aires, Cedodal, 2011.

Hanley, Keith y Walton, John, Constructing Cultural Tourism: John Ruskin and the Tourist Gaze, Bristol, Buffalo y Toronto, Channel View Publications, 2010.

Jordi, Jorge Alberto y Victoria, Lisandro Fausto, Nacimiento y muerte de la maravilla del siglo xx. Club Hotel de la Ventana, Buenos Aires, Dunken, 2009.

Lacoste, Pablo, «El Ferrocarril Trasandino y la construcción de la cordillera como espacio social (1893-1947)», Entrepasados, N. ${ }^{\circ}$ 24-25, 2003, pp. 177-197.

Losada, Leandro, La alta sociedad en la Buenos Aires de la Belle Epoque, Buenos Aires, Siglo Veintiuno Editores, 2008.

Marrey, Bernard, «Un siglo de hoteles», Summa, Colección temática N. ${ }^{\circ} 20$, Arquitectura hotelera, Buenos Aires, Ediciones Summa, 1987, pp. 12-14.

McLaren, Brian, «De Trípoli a Gadames: arquitectura y la experiencia turística de la cultura local en la Libia colonial italiana», en: Medina Lasansky, D. y McLaren, Brian (eds.), Arquitectura y turismo. Percepción, representación y lugar, Barcelona, Gustavo Gili, 2006.

Pastoriza, Elisa, La conquista de las vacaciones. Breve historia del turismo en la Argentina, Buenos Aires, Edhasa, 2011.

----- y Torre, Juan Carlos, Mar del Plata: un sueño de los argentinos, Buenos Aires, Edhasa, 2019.

Pevsner, Nikolaus, Historia de las tipologías arquitectónicas, Barcelona, Gustavo Gili, 1980.

Rodríguez, Stella Maris y Rodríguez, Sergio, Club Hotel de la Ventana. La historia de un gigante, Buenos Aires, Ediciones Pensamiento, 2001.

Sandoval-Strauz, Andrew, «Why the Hotel? Liberal Visions, Merchant Capital, Public Space, and the Creation of an American Institution », Business and Economic History. V. 28, N. ${ }^{0}$ 2, 1999.

----—, Hotel. An American history, Yale: Yale University Press, 2007.

Scandizzo, Delfor, «Los avatares del Club Hotel», Todo es Historia, N. ${ }^{\circ} 439,2004$, pp. 50-51.

Scarzanella, Eugenia, «Las bellezas naturales y la Nación: los Parques Nacionales en la Argentina en la primera mitad del siglo xx», en Revista Europea de Estudios 
Latinoamericanos y del Caribe, N. ${ }^{\circ}$ 73, 2002, pp. 5-21. Disponible en: https://www.jstor.org/stable/25675985?seq=1.

Scobie, James, Buenos Aires del centro a los barrios 1870-1910, Buenos Aires, Ed. Solar, 1986.

Dunant, Jacques y Mallet, Gastón, Hotel de la Sierra de la Ventana, en Hébert, George (Ed.), Arquitectura y decoración en Sud-América, Buenos Aires, Ed. George Hébert, 1913.

Withey, Lynne, Grand tours and Cook's tours: a history of leisure travel, 1750 to 1915, Nueva York, William Morrow and Company, 1997.

Zenequelli, Lidia, El Tigre Hotel y el Tigre Club, Buenos Aires, Dunken, 2005. 